Pero ¿qué es el bioarte?

María de las Mercedes Reitano

Boletín de Arte (N. ${ }^{\circ}$ 19), e017, septiembre 2019. ISSN 2314-2502

https://doi.org/10.24215/23142502e017

http://papelcosido.fba.unlp.edu.ar/ojs/index.php/boa

Facultad de Bellas Artes. Universidad Nacional de La Plata

La Plata. Buenos Aires. Argentina

\title{
PERO ¿QUÉ ES EL BIOARTE?
}

\section{BUT, WHAT IS BIOART?}

\author{
María de las Mercedes Reitano \\ reitanomariam@yahoo.com
}

Instituto de Historia del Arte Argentino y Americano. Facultad de Bellas Artes

Universidad Nacional de La Plata. Argentina

Recibido: 12/3/2019

Aceptado: 16/6/2019

Reseña a la muestra Cosas extrañas. Bioarte en la Argentino (2019).

Curaduría: Natalia Matewecki y Daniel López del Rincón.

Centro de Arte UNLP, La Plata. 13 de abril al 18 de mayo de 2019.

\section{RESUMEN}

Esta reseña plantea una reflexión en torno a la muestra Cosas extraños. Bioarte en la Argentino, realizada entre el 13 de abril y el 18 de mayo de 2019 en el Centro de Arte UNLP. La exposición reúne once producciones artísticas nacionales que vinculan arte, biología y tecnología. Todas ellas forman parte del bioarte, una categoría que agrupa propuestas que se nutren de experiencias del mundo científico-técnico y del artísticohumanístico. En líneas generales, las obras exhibidas interpelan diferentes conceptos, tales como: la materia, la forma, el tiempo y el espacio.

Palabras clave

Bioarte; argentino; arte; ciencia; tecnología

\section{ABStRACt}

This review raises a reflection around the exhibition Strange Things. Bioart in Argentina, held between April 13 and May 18, 2019 at the Art Center UNLP. This exhibition brings together eleven argentinian artworks which connect art to biology and technology. They are part of a field known as bioart, which draws on experiences from both the technical-scientific world and the artistic-humanistic one. In general, the exhibited works address different concepts such as: matter, form, time and space.

\section{KEYWORDS}

Bioart; argentinian; art; science; technology 
A medida que los elementos de producción biológica penetran las obras, la actitud estética se reafirma. La muestra cosas extraños nos habla de otra coso, otro universo productivo que se aleja de los elementos plásticos tradicionales y nos enfrenta a una indagación que oscila entre la investigación científica y la recuperación estética.

En la sala B del Centro de Arte UNLP se exhiben las obras: Instalación de orquídeas in vitro y Umbilical, del Grupo Proyecto Untitled; Proyecto Biosfera y Big Brain Project, de Joaquín Fargas; Capturas y Mis plantas (representaciones dinámicas), de Luciana Paoletti; Síntesis simbiótica entre un ser vivo y una máquina, de Marina Zerbarini; Generación de conciencia, de Daniel Álvarez Olmedo y Guido Villar; Morfogénesis S/Z, de Agustín Bucari; Colonia, de Darío Sacco y, junto con Gabriel Cicuttin, la performance Oscilaciones Bacterianas.

Las propuestas de estos artistas/investigadores/divulgadores develan un mundo invisible, próximo y lejano al mismo tiempo, y presentan una constelación de prácticas que abarcan una buena parte de los desarrollos del bioarte actual. De inmediato, surgen numerosas cuestiones alrededor de tales propuestas dirigidas a promover una nueva práctica artística, donde, a menudo, el paratexto de la obra cobra un desafiante énfasis.

Pero, ¿qué es el bioarte? Para Daniel López del Rincón (2015) el término bioarte designa «un conjunto de prácticas artísticas que relacionan arte, biología y, muy frecuentemente, tecnología» (p. 11). Es un término amplio que reúne un grupo heterogéneo de prácticas y dispositivos. El año 2008 es clave para el bioarte local al crearse el primer Laboratorio Argentino de Bioarte en la Universidad Maimónides, en la ciudad de Buenos Aires.

Durante el recorrido de la exhibición no nos dejamos de asombrar ante la complejidad de la producción y la emancipación de las obras. Algunos artistas que provienen del campo de la ciencia y otros de las artes visuales congregan sus reflexiones e indagan sobre otras posibilidades, abandonan las jerarquías tradicionales de los medios de expresión para adoptar el dispositivo que mejor les resulta a sus indagaciones. Las obras expuestas abordan diversas temáticas a través de la investigación científica y la experiencia estética. En este sentido, los artistas indagan en prácticas de altísima movilidad, se interrogan sobre la temporalidad y las potencialidades de los distintos medios materiales.

Como se señala en el catálogo de la exposición (Matewecki \& López del Rincón, 2019), las once obras que conforman la muestra interpelan diferentes conceptos, tales como la materia, la forma, el tiempo y el espacio. Estas producciones son un ejemplo típico de las consideraciones que presenta el arte contemporáneo, un permanente compromiso con el efecto de belleza y con la tarea de introducir al espectador en una situación de asombro, de desconcierto, que lo obliga a tomarse un tiempo antes de que la obra ofrezca la información suficiente acerca de sí misma, para que sea posible, de alguna manera, decodificarla.

Al respecto, Terry Smith (2012) sostiene que el arte contemporáneo «propone o exige muchas clases de tiempo por parte del público y, a cambio de ello, ofrece mucho» (p. 245). Razón por la que estas obras, que son producto de intensos trabajos de investigación y experimentación -y que por la interacción humano/ciencia/naturaleza/máquina suponen diversas demandas a los espectadores-, señalan un espacio físico o virtual, una parte del mundo que pasa a estar dominado por la provisionalidad, el tiempo y la posibilidad.

Estos artistas plantean interrogantes acerca de la temporalidad de la naturaleza, exploran experiencias de localización e interactividad mediada. Podríamos decir que una de las características de sus obras es la condición de procesual, tanto en sus formas como en sus métodos, ya que en lugar de estar orientadas hacia el objeto terminado, cobran significado a través de su proceso de exhibición y recepción. 
Asimismo, las distintas producciones se distinguen por el uso de métodos colaborativos, al adquirir una importancia central la investigación preliminar y el trabajo de laboratorio. Las técnicas y los métodos utilizados provienen de modos de hacer que están por fuera del mundo del arte. En conjunto, estas prácticas expanden las fronteras del arte redefiniendo, entre otras cosas, el papel del artista.

En la experiencia directa con la obra, los efectos de la misma, que continúan más allá de la exhibición, expanden su alcance a través de los documentos o de la reflexión en torno a los videos y las experimentaciones. La noción de situación reconduce la unidad de tiempo, de lugar y de acción en un escenario que implica una relación con el otro y con el mundo. En estas obras los modos de hacer se ejercen en sí mismos, basta con recorrerlas y reconocerlas. Ellas narran su génesis y su poética, su existencia en la inmanencia.

\section{REFERENCIAS}

López del Rincón, D. (2015). Bioarte. Arte y vida en la era de la biotecnología. Madrid, España: Akal.

Matewecki, N. y López del Rincón, D. (2019). Cosas extrañas. Bioarte en la Argentino [Catálogo de exposición]. La Plata, Argentina: Centro de Arte UNLP, Universidad Nacional de La Plata.

Smith, T. (2012). ¿Qué es el arte contemporáneo? Ciudad Autónoma de Buenos Aires, Argentina: Siglo Veintiuno. 